\title{
Da abundância do agronegócio à Caixa de Pandora ambiental: a retórica do desenvolvimento (in) sustentável do Mato Grosso (Brasil)*
}

From the abundance of agrobusiness to Pandora's environmental Box: the rhetoric of (non) sustainable development in Mato Grosso (Brazil)

\section{De l'abondance de l'agriculture à la Boîte de Pandora environnemental: la rhétorique} du développement (in)soutenable de Mato Grosso (Brésil)

De la abundancia del agronegocio a la Caja de Pandora ambiental: la retórica del desarrollo (in) sustentable de Mato Grosso (Brasil)

\author{
Andréa Aguiar Azevedo** \\ Richard Pasquis**
}

Recebido em 20/1/2007; revisado e aprovado em 29/3/2007; aceito em 27/7/2007

\begin{abstract}
Resumo: O objetivo do texto é discutir o desenvolvimento do estado do Mato Grosso nos últimos anos, além de avaliar a contribuição do desmatamento para geração de riquezas que possam se converter em ganhos para a sociedade regional. Por meio de um exercício empírico é revelado, num panorama inicial, que não existem diferenças socioeconômicas muito marcantes entre municípios que foram desmatados com maior ou menor intensidade, sobretudo entre aqueles onde a atividade econômica predominante é a pecuária (bovinocultura).

Palavras-chave: desenvolvimento; desmatamento; indicadores socioambientais.
\end{abstract}

Abstract: The objective of this paper is to discuss the State of Mato Grosso's development over the past years as well as to evaluate deforestation contribution to wealth creation, which can be converted into benefits for its population. Through an empiric exercise, it is clear that, in an overview, there are no striking social and economic differences between cities or towns that had more or less deforested sites, especially where the main economic activity is cattle breeding (bovine culture).

Key words: development; deforestation; socioenvironmental indicators.

Résumé: Le but du texte est discuter le développement de l'état de Mato Grosso dans les dernières années et évaluer la contribution du déboisement pour la génération des richesses qui puisse bénéficer la société régionale. À partir d'un exercice empirique, on révèle, dans um panorama initial qu'il n'y a pas de différences socio-économiques prononcées parmi les villes qui ont été déboisées en majeure ou en mineure intensité, surtout parmi lesquelles l'activité économique predominante est l'élevage bovin.

Mots-clé: développement; déboisement; indicateurs socio-environnemental.

Resumen: El objetivo del texto es discutir el desarrollo del estado de Mato Grosso en los últimos años, además de evaluar la contribución de la deforestación para generación de riquezas que puedan convertirse en ganancias para la sociedad regional. Por medio de un ejercicio empírico es revelado, en un panorama inicial, que no existen diferencias socioeconómicas muy marcantes entre municipios que fueron deforestados con mayor o menor intensidad, sobre todo entre aquellos que la actividad económica predominante es la pecuaria (bovinocultura).

Palabras clave: desarrollo; deforestación; indicadores socioambientales.

\section{Introdução}

O estado do Mato Grosso vem apresentado um crescimento considerável em sua economia. A dinâmica do estado se diferencia dos outros estados da Amazônia Legal, tanto por apresentar o maior Produto Interno Bruto ao longo dos últimos anos, quanto por apresentar as maiores taxas de desma- tamento. Essa dinâmica foi mais alterada na década de 80 e 90 com a entrada da soja no estado e a sua consolidação como o maior produtor dessa commodity no país.

A industrialização da agricultura a transforma em agribusiness, o rural se moderniza e, junto com esse processo, traz também problemas da civilização industrial para o campo. A diferença é que, nesse momen-

\footnotetext{
* Artigo apresentado no XLIV Congresso da Sociedade Brasileira de Economia e Sociologia Rural (SOBER) em Fortaleza-CE, no período de23 a 27 de julho de 2006.

** Mestre em Gestão Econômica do Meio Ambiente (ECO/ UnB) e doutoranda em Desenvolvimento Sustentável pelo CDS/ UnB; bolsista CAPES; docente da Faculdade do Sul do Mato Grosso (FACSUL/CESUR). E-mail: aaabio@terra.com.br; aazevedo@unb.br

*** Doutor em Geografia pela Universidade de Paris VII; pesquisador do CIRAD (França) e pesquisador visitante do Centro de Desenvolvimento Sustentável da Universidade de Brasília. E-mail: pasquis@terra.com.br
} 
to, a sociedade já tem noção dos "limites impostos ao crescimento" e dos custos da modernização. Por isso, há uma busca de alguns setores da sociedade, por um desenvolvimento que leve em consideração a racionalidade ecológica e a justiça social.

O que precisa ser entendido é a dimensão real que o termo desenvolvimento deveria traduzir, que vai muito além da esfera econômica. Entendido isso, não haveria necessidade de um "sustentável" ao lado, na atenta lembrança de como deveria sê-lo. Assim, com o esvaziamento do sentido de desenvolvimento, busca-se uma mudança de modelo que supere semânticas, conceitos e boas intenções. Não só o Estado deve atuar nessa mudança, mas também, e, sobretudo, a sociedade civil num processo democrático cada dia mais participativo e com a maior legitimidade possível. Boaventura dos Santos (2001) argumenta que deve haver um maior equilíbrio entre as forças regulatória do mercado, Estado e sociedade. Além disso, nesse novo projeto deve haver lugar para incerteza e precaução.

Nesse sentido, é apresentado no texto um panorama do desenvolvimento do estado do Mato Grosso, bem como a sua inserção no agronegócio, por meio de mudanças na economia mundial e nacional. Autores como Celso Furtado, Sunkel, Caio Prado Jr., Amartya Sen e Ignacy Sachs foram a base da referencia teórica para discussão sobre desenvolvimento que norteiam esse texto. Além disso, foi feita uma análise empírica, utilizando-se alguns indicadores econômicos e sociais e cruzando-os com índices de desmatamento relativo em alguns municípios do estado. Foram analisados os cinco municípios mais desmatados e os cinco que menos tiveram área de cobertura vegetal original convertida (até o ano de 2004), na tentativa de entender melhor as incongruências na forma do desenvolvimento adotado pelo estado. Além disso, também foram analisados alguns indicadores socioeconômicos e ambientais dos 10 municípios no estado mais desmatados entre os anos de 1993 e 2003.

\section{Desenvolvimento: teorias e práticas de um processo desigual}

Não obstante, a conotação econômica que impregna a palavra desenvolvimento, sabe-se que ele deve ir muito além dessa esfera. O modo de o homem moderno pensar o desenvolvimento, no contexto do capitalismo, é impregnado pelo ideário iluminista e propulsionado pela ciência moderna, cuja racionalidade é pautada pela valorização do individualismo, do utilitarismo, da separação e da simplificação.

Furtado (2000) ilustra bem essa forma de pensar da civilização ocidental moderna, quando diz que o comportamento racional é relacionado com o comportamento eficiente que, por sua vez, é traduzido por meio do progresso técnico. "O progresso técnico é fruto da criatividade humana, da faculdade do homem de inovar. Portanto, o que cria o desenvolvimento é essa faculdade que possibilita o avanço da racionalidade no comportamento" (FURTADO, 2000, p.43). A concretização máxima dessa racionalidade ligada à técnica tem na revolução industrial seu ponto de partida. Por meio dela, o mundo experimenta uma mudança expressiva na forma de lidar com a natureza e com os produtos dela oriundos. Nesse momento, começa, com maior força, a "privatização/mercantilização da natureza" e um processo infindável de acumulação.

A Revolução Industrial, contrariando um pensamento linear, gerou desenvolvimentos diferenciados em função de fatores e condições distintas entre os países. Assim, de acordo com seu grau de desenvolvimento, os países receberam a denominação de desenvolvidos (centrais) ou subdesenvolvidos (periféricos). A revolução industrial início do capitalismo - rompeu com o modelo anterior, mudando a forma e a lógica de produção e de acumulação de riquezas. Esta levou ao surgimento de um sistema de relações econômicas internacionais, numa das maiores globalizações mercantilistas que existiram na história econômica, propiciando a conformação das economias periféricas (SUNKEL, 1967).

Desde o início desse processo, o Brasil ocupou uma posição de economia periférica, iniciada no período colonial. $\mathrm{Na}$ divisão 
internacional do trabalho, consolidou-se como provedor de matéria prima para os países centrais por meio de diversos ciclos agrícolas e pela exportação de minérios. Assentado na produção agrícola, com um modelo tradicional de monocultura voltado para fora, o país foi construindo uma estrutura social marcada por fortes desigualdades econômicas, além de raramente ter a pauta de produção nacional baseada na preferência alimentar do contexto sócio cultural brasileiro. Prado Jr (1999, p.71) realça que, na construção desse processo, existe uma "retroação da superestrutura social sobre a base econômica que a determina". Dessa forma, a organização da produção para o mercado externo determinará uma estrutura incapaz de proporcionar um mercado interno apreciável e estimulante de atividades produtivas de nível elevado e de grandes perspectivas (idem).

Não obstante, com a organização social que o sistema ia criando, o país acumulou um excedente, derivado, sobretudo do ciclo do café, que somado às contingências do mercado internacional durante a crise mundial na década de 30 - diminuição na compra dos produtos primários e restrição para importação de produtos manufaturados - possibilitou o seu primeiro surto de industrialização mais efetivo, através da substituição às importações. É o que Furtado (2000) chamou de "industrialização reativa". Essa industrialização aconteceu para suprir uma demanda interna que embora começasse a se diversificar e dinamizar, ainda era restrita. Assim, o Brasil se encontrava no dilema dos países de periferia dentro do sistema do comércio internacional: sua perspectiva de crescimento era limitada, caso o consumo se restringisse somente ao mercado interno, e, por outro lado, suas chances de inserção no mercado internacional, por meio da industrialização, eram mínimas diante de sua nítida desvantagem tecnológica.

Furtado (2000, p. 82) esclarece que "[...] o que veio a se chamar de subdesenvolvimento não é outra coisa senão a manifestação dessa disparidade entre o dinamismo da demanda e o atraso na acumulação reprodutiva". Nesse sentido, o Estado teve um papel muito importante, sobretudo nesse esforço para construção de indústrias de base para fortalecer o processo de industrialização e a criação de um sistema financeiro especializado.

Foi nesse cenário que começaram a aparecer as primeiras empresas transnacionais que, como o nome sugere, buscavam ir além do fechamento político de seus territórios nacionais, aproveitando o surgimento de novas oportunidades econômicas onde quer que elas estivessem. Esse processo acelerouse particularmente após 1950. Para além dos consumidores, o que atraía essas empresas era a baixa remuneração da mão-de-obra e a capacidade de utilizar as técnicas já disponíveis, ademais tornavam-se fortalecidas nos países centrais de origem. Assim, nessa tentativa de mudança na divisão internacional do trabalho, por meio da instalação das transnacionais, aparece uma "periferia semiindustrializada controlada do centro e orientada em boa parte para o mercado deste" (FURTADO, 2000, p. 122).

Após a década de 80, os países são estimulados em direção a uma crescente abertura dos mercados internacionais, indicando uma redução do papel do Estado nas economias nacionais. Nessa fase de retomada do liberalismo econômico, as indústrias dos países periféricos tiveram que enfrentar um processo de "modernização à força". Nesse processo, mais uma vez, os países em desenvolvimento recorreram às importações, consolidando o papel de consumidores de tecnologia, sobretudo, de alta tecnologia.

Atualmente, desde do inicio da década de 1990, quando se analisa a pauta de exportação brasileira, observa-se que o país não consegue competir nos setores mais dinâmicos com utilização de alta tecnologia - com honrosas exceções aos setores de siderurgia e de transporte aéreo. Em compensação, reafirmou sua nossa posição como exportador de commodities agrícolas e produtos intensivos em trabalho e recursos naturais. A associação com o seu passado colonial é inevitável, obviamente, atentando para as enormes diferenças. O caso é que, além de estar se especializando cada vez mais em setores que não são dinâmicos dentro do comércio internacional, o Brasil está vendendo produtos com rentabilidade decrescente ao longo do tempo, dilapidando nossas riquezas naturais num sistema de troca injusto e pro- 
movendo a manutenção de uma estrutura social que reduz, cada vez mais, o salário do trabalhador dentro do processo produtivo.

Assim, a sociedade atual vive dilemas sérios, que fazem com que se questione cada vez mais esse modelo de desenvolvimento capitalista ocidental, iniciado a partir da Revolução Industrial. Um desses graves dilemas é o enfrentamento da questão social e ambiental. O problema ecológico, somente em meados da década de 60, começou a ser considerado dentro da economia. Na próxima seção será descrito brevemente esse processo com a intenção de desvelar um pouco o paradigma que restou nessa história: o desenvolvimento sustentável.

\section{$2 \mathrm{O}$ "sustentável" do desenvolvimento}

A partir das décadas de 60/70, inúmeras alterações ocorreram no cenário econômico e político das relações centro-periferia em nível mundial. Dentre elas, se destacam: (a) a crise energética e econômica, com a aceleração de tendências ao desenvolvimento e incorporação de tecnologias 'mais limpas' aos processos produtivos; (b) o surgimento da crise ambiental como questão política no desenvolvimento econômico e nas relações internacionais (Estocolmo 1972; Brundtland, 1987, Rio 1992); e (c) a hegemonia políticoideológica do capitalismo (com fim da URSS e a derrubada do bloco socialista).

Como resultado da discussão das possibilidades entre crescimento econômico e conservação ambiental, o desenvolvimento sustentável (DS) parece ter sido a herança oficial deixada pelos organismos internacionais dentro da agenda política mundial. No entanto, essa foi impulsionada/inflada pelos movimentos da sociedade civil organiza$\mathrm{da}$, sobretudo o ambientalista na última metade do século XX. Após o conceito oficial de DS ter sido revelado, a partir do relatório "Nosso Futuro Comum", em 1987, ele tem sido amplamente discutido, especialmente nos meios acadêmicos, sobre sua factibilidade e sua falta de clareza teórica.

Para melhor ilustrar as diferentes posições acadêmicas e políticas, Veiga (2005) sugere que nessa briga por território conceitual co-existem duas idéias contrárias e um "quase" caminho do meio.
O primeiro caminho seria aquele que não percebe nenhuma incompatibilidade entre crescimento econômico e conservação ambiental. Nesse sentido, segundo esses teóricos a degradação ambiental existiria até certo ponto da renda per capita. Depois de alcançado determinado nível de renda (média US\$ 8.000,00), a tendência é que a degradação diminua. Representantes desse pensamento são Kuznets, Grossman \& Krueger. O caso é que nessa realidade complexa de desenvolvimento, existem exemplos de inúmeros países com altíssimas rendas per capita e que, nem por isso, apresenta baixos índices de degradação.

Os economistas neoclássicos ambientais se apropriaram dessa lógica e muitos ainda acreditam que o crescimento econômico, capitaneado pela economia de mercado, vai se revelar um grande indutor da sustentabilidade. Segundo a economia ambiental de matriz neoclássica, o problema está centrado em dois eixos: nos preços baixos dos recursos naturais e na falta de preços dos bens ambientais livres. Para corrigir tais falhas, haveria a necessidade de internalizar os custos ambientais e sociais - provocados pela degradação/exploração - dentro dos custos privados. Isso elevaria o preço e diminuiria a demanda por tais recursos, o que levaria os produtores a buscarem "tecnologias mais limpas". Para o segundo eixo do problema, eles criaram o instrumental da valoração ambiental que "precificaria" a natureza por meio de métodos de surveys junto à população. No entanto, há várias críticas tanto em relação ao significado moral e ético dessa atitude, quanto aos métodos empíricos que viabilizariam um preço. Como se percebe, essa escola de economistas ainda demonstra uma forte crença na reversibilidade e passividade dos ecossistemas e um grande otimismo nas tecnologias e no mercado.

$\mathrm{Na}$ outra ponta se encontra, como principal representante, Georgescu Roegen que não acredita na compatibilização da economia e conservação, se mantido esse modo de produção intensiva em recursos naturais. Georgescu utiliza-se do conceito de entropia da segunda lei da termodinâmica, para mostrar que se tira da natureza energia de baixa entropia e, através da produ- 
ção, essa energia aumenta a entropia resultando em energia dissipada e não reutilizável pelos humanos. Anuncia que a tendência da humanidade em algum momento do futuro é que desenvolva uma economia de retração, com a diminuição do produto.

O caminho do meio que, segundo Veiga (2005), não chega a ser propriamente isso, vem também de uma linha mais crítica e cética em relação ao crescimento econômico. Ele se encontra na proposta de Daly que indica que a superação dos problemas ambientais só viria por meio de um "crescimento qualitativo". Seria um estado estacionário para países que já estão desenvolvidos e com fartura material. Não obstante, nessa situação, as tecnologias continuariam a se desenvolver, procurando melhorar qualitativamente a produção. Desta forma, para Daly, desenvolvimento sustentável representa o desenvolvimento sem crescimento, pelo menos para os mais ricos.

Em busca de qualificações das possíveis posições apresentadas, Veiga (2005) questiona como reagem os economistas diante das diversas visões que variam da mais otimista (neoclássica), passa pela apocalíptica de Georgescu e entra no que ele denominou de "evangélica" de Daly. Segundo ele, a maioria ainda ignora essas questões. Quem aparece com algumas alternativas é Ignacy Sachs que propõe a apreciação da sustentabilidade por meio de diversas dimensões que estariam conectadas. Sem entrar em detalhes nessa "compartimentalização" da sustentabilidade, o que Veiga sugere é que o desenvolvimento sustentável, no futuro, seria uma superação (no conceito dialético) entre o capitalismo e o socialismo (!).

Tentando dialogar com a suposição de Veiga, poderíamos dizer que essa superação homogênea é muito improvável, sendo mais realístico, pensarmos em um processo dialógico, já que as diversas ideologias conviveriam num mesmo espaço, buscando dentro de suas lógicas, a sustentabilidade.

O que "imobiliza" a idéia de DS, numa perspectiva mais sociológica, é a centralidade que a economia ocupa. Esse pensamento é corroborado pelo de Sen (2005), que retira essa centralidade da economia e da renda, do processo de desenvolvimento. Nas teses de Sen (2000) a renda é concebida não como o único meio para alavancar o desenvolvimento. Segundo ele, o importante para o desenvolvimento seria a existência das liberdades substantivas que fariam com que os indivíduos exercessem suas capacidades (ler, escrever, ter saúde, participar politicamente, poder fazer escolhas, etc.). O enfoque alternativo, proposto por Sen (2000), incide sobre as liberdades geradas pelos bens e não sobre os bens em si mesmos. Em suas palavras: "venho procurando demonstrar já há algum tempo que, para muitas finalidades avaliatórias, o 'espaço' apropriado não é o das 'utilidades' (como querem os welferista), nem o dos bens primários (como exigido por Rawls ${ }^{1}$ ), mas o das liberdades substantivas as capacidades - de escolher uma vida que se tem razão para valorizar" (SEN, 2000, p.91).

Assim, por meio desse marco teórico, que retira a centralidade do aspecto econômico do conceito de desenvolvimento, mas que claramente também não o prescinde, buscamos analisar o caso último surto de desenvolvimento do estado do Mato Grosso, especialmente no período do início da década de noventa até 2003.

\section{Mato Grosso: nasce a nova fronteira agrícola}

Mato Grosso atualmente tem 142 unidades municipais e ocupa uma área de $906.807 \mathrm{~km}^{2}$. Embora a densidade demográfica seja ainda baixa, sua população aumentou 6,37 \% de 1991 a 2002. A população estimada para 2005 (IBGE) foi de 2.803.274 habitantes. Essa história que mostra um crescimento em todos os aspectos é uma tentativa de inclusão no modelo de modernização espelhado nos países capitalistas desenvolvidos.

Após 1930, começa a se acentuar o processo de colonização do Mato Grosso, promovida pelo governo, iniciada no sul do estado $^{2}$, onde tiveram preferência os migrantes nacionais. A partir da década de 60 , essas colônias entraram em decadência, com uma maior concentração fundiária. Em 1971, o INCRA (Instituto Nacional de Colonização e Reforma Agrária) transfere o processo de colonização para o setor privado, que inicia a colonização no norte do estado. Havia, naquele período, a clara intenção de 
ocupação da Amazônia Legal, em especial o MT e o Pará. Foram construídas grandes obras de infra-estrutura como a BR 163 (Cuiabá - Santarém) e a BR 364 (Cuiabá - Porto Velho). Nesse sentido, na década de 70, deuse início a ocupação da nova fronteira agropecuária que começava a ser incorporada aos espaços produtivos do estado. As novas rodovias foram fundamentais nessa nova incorporação (BERTRAN, 1988), que foi realizada basicamente por migrantes oriundos do Sul do país.

Os estados do Centro Oeste e do Norte se inserem, nesse período, no contexto da história política brasileira de apoio à modernização da agricultura e avanço sobre as novas fronteiras. Graziano da Silva (1998, p.50) indica que este apoio começa a se revelar mais plenamente com as políticas de crédito subsidiado, com a criação do SNCR (Sistema Nacional de Crédito Rural). Este estímulo ao crédito a baixo custo, um acentuado desenvolvimento do aporte técnico e o incremento genético no setor, além de programas de incentivo como Polocentro, Proterra, Prodecer e outros ${ }^{3}$ que foram importantes na condução da "modernização conservadora" da agricultura no estado do Mato Grosso. Assim, nos primeiros anos da modernização agrícola houve um aumento expressivo da produtividade, entretanto, no período posterior, começam a aparecer os primeiros sinais da "ressaca" socioambiental advindos desta forma de exploração intensiva, notadamente, em ambientes onde predominam as monoculturas.

Na década de 80, o Brasil entra numa crise profunda, com a queda no produto real da indústria e do PIB, além do aumento do desemprego e perda do valor do salário. Neste contexto, a agricultura foi estimulada (novamente) a funcionar como geradora de divisas para o país, sendo a produção de ali- mentos relegada a segundo plano, com um desempenho pouco satisfatório. Mueller, Wriht e Nogueira (1986, p.82) apontam que, desde a década de setenta a agricultura já era pressionada para canalizar a produção para geração de divisas, além da produção de energéticos advinda da necessidade de substitutos após a crise do petróleo. Desta forma, as políticas púbicas foram direcionadas para esses fins.

Nos anos 90, consolida-se, em nível nacional, a concepção de sistema ou complexo agroindustrial. Nessa etapa a indústria começa a fazer parte do negócio e Malassis (em GRAZIANO SILVA, 1998, p.67) enfatiza a dimensão histórica do complexo agroindustrial como característico da etapa do desenvolvimento capitalista em que a agricultura se industrializa. Desta forma, na agricultura, percebe-se uma profunda dependência de insumos químicos, mecânicos e genéticos de origem industrial, bem como o destino igualmente industrial de boa parte da produção.

No Mato Grosso, esse fenômeno aconteceu fortemente nas décadas de 1980 -1990 e adentrou o século XXI, sobretudo, por meio da produção de soja. O Produto Interno Bruto (PIB) do estado vem mostrando um crescimento bem acima da média nacional: entre 1994 e 2002, ele cresceu $5,6 \%$ vis a vis ao PIB nacional, que foi de 2,7\%. De todos os estados da Amazônia Legal, o Mato Grosso é que vem contabilizando o maior PIB per capita nos últimos anos (até 2003), ficando atrás somente do estado do Amazonas. Entretanto, o lado não contabilizado do PIB no estado pode ser mostrado pelo crescente índice nos desmatamentos. Também dentro da Amazônia Legal, é o estado que mais contribui para esse incremento. O quadro 1, abaixo, mostra a totalização desses dados dentro do estado.

\begin{tabular}{|c|c|c|c|}
\hline $\begin{array}{c}\text { Desmate total absoluto } \\
\text { até 2004 (ha.) }\end{array}$ & $\begin{array}{c}\text { Desmate total relativo } \\
\text { até 2004 (\%) }\end{array}$ & $\begin{array}{c}\text { Desmate absoluto } \\
\mathbf{1 9 9 3 - 2 0 0 4} \text { (ha.) }\end{array}$ & $\begin{array}{c}\text { Desmate relativo } \\
\mathbf{1 9 9 3 - 2 0 0 4}(\mathbf{\% )}\end{array}$ \\
\hline $28.842 .582,00$ & 31,84 & $12.822 .822,00$ & 13,29 \\
\hline
\end{tabular}

Quadro 1 - Total de desmatamento no Estado do Mato Grosso acumulado até o ano de 2004. 
Nota-se que entre 1993 e 2004 houve uma intensificação nos desmates dentro do MT. Considerando o total desmatado no estado até hoje $(31,84 \%=100)$, o período mencionado $(13,29 \%)$ contribuiu com $41 \%$ do total dos desmates no estado feitos até hoje.

Será que se pode dizer que os municípios mais desmatados apresentam melhores indicadores econômicos e sociais? Intuitivamente, pode-se responder de forma positiva, no entanto, trabalhando com dados empíricos de municípios de Mato Grosso observamos que os mais desmatados do estado (grupo 1 a 4), como se observa na Tabela 1, apresentam tanto PIB per capita, quanto IDH (Índice de Desenvolvimento Humano) equivalentes aos outros, menos desmatados, que estão na segunda parte da tabela (grupo 5 a 8). A única exceção é o município de Alto Taquari (4), que possui um IDH alto e um PIB per capita bem superior à média estadual e nacional. O que deve ser levado em conta nessa análise é que, não obstante ele tenha um PIB per capita bastante elevado ( $\mathrm{R} \$ 32.671,00)$, por causa da produção de soja e de serviços (Ferrovia Ferronorte), apresenta uma taxa de desmatamento de $82,6 \%$ em relação a sua área.
Além disso, o índice de Gini, que mede a desigualdade de renda, revelou um aumento substancial em dez anos. No ano de 1991, a taxa era de 0,54 para esse município e, em 2000, passou para 0,70, índice bem superior à média do estado, que, em 2000, era de 0,63.

Dentre os municípios que menos desmataram (grupo de 5 a 8), o IDH médio mais baixo é para renda, no entanto, em educação e longevidade, eles são compatíveis com os outros municípios mais desmatados. Além disso, nesse grupo, houve diminuição do índice de desigualdade de renda entre 1991 e 2000 , sendo que a relação dos $20 \%$ mais ricos em relação aos $40 \%$ mais pobres é menor que a média estadual de $17,04 \%$. A única exceção nesses dois indicadores foi Cotriguaçu, que aumentou as desigualdades de acordo com a comparação do Gini entre 1991 e 2000. Outro dado importante é sobre o município de Aripuanã. Até 2003, ele mantinha $8,4 \%$ de toda sua área aberta. No ano de 2004, foi campeão de desmate aumentado em 1,76\% esse valor. Apesar de o município ainda possuir ativo florestal, esses dados indicam um avanço da fronteira em direção ao sul do Amazonas.

Tabela 1 - Comparação de indicadores sociais e econômicos em relação aos índices de desmatamento (4 municípios desmatados entre os 10 com maior conversão/ 4 municípios entre 10 com menor conversão)

\begin{tabular}{|c|c|c|c|c|c|c|c|c|c|c|c|c|}
\hline \multirow[t]{3}{*}{ ID } & Município & $\begin{array}{c}\text { Desmate } \\
\text { absoluto até } \\
2003 \text { (ha.) }\end{array}$ & $\begin{array}{c}\text { Desmate } \\
\text { relativo } \\
\text { total }\end{array}$ & $\begin{array}{c}\text { Desmate } \\
\text { relativo } \\
1993-2003\end{array}$ & $\begin{array}{c}\text { IDH/M (1) } \\
(2000)\end{array}$ & $\begin{array}{l}\text { IDHM } \\
\text { Renda } \\
(2000)\end{array}$ & $\begin{array}{c}\text { IDHM } \\
\text { Educação } \\
(2000)\end{array}$ & $\begin{array}{l}\text { IDHM } \\
\text { Long. } \\
(2000)\end{array}$ & $\begin{array}{c}\text { Índice de } \\
\text { Gini (2) } \\
\text { (1991) }\end{array}$ & $\begin{array}{l}\text { Índice } \\
\text { de Gini } \\
(2000)\end{array}$ & $\begin{array}{c}20 \% \text { mais } \\
\text { ricos/ } 40 \% \\
\text { mais pobres } \\
(2000)\end{array}$ & $\begin{array}{c}\% \text { de } \\
\text { Domicílio com } \\
\text { Abastecimen- } \\
\text { to de Água } \\
(2000)\end{array}$ \\
\hline & Brasil & - & - & - & 0,766 & 0,723 & 0,849 & 0,727 & 0,63 & 0,65 & 21,40 & 77,82 \\
\hline & $\begin{array}{l}\text { Mato } \\
\text { Grosso }\end{array}$ & $28.842 .582,00$ & 31,84 & 13,29 & 0,773 & 0,718 & 0,86 & 0,74 & 0,60 & 0,63 & 17,04 & 63,67 \\
\hline 1 & $\begin{array}{l}\text { São Jose } \\
\text { dos Quatro } \\
\text { Marcos }\end{array}$ & $122.504,1$ & 95,6 & 15,5 & 0,735 & 0,628 & 0,832 & 0,745 & 0,54 & 0,49 & 8,79 & 63,95 \\
\hline 2 & Rio Branco & $44.494,1$ & 88,78 & 14,1 & 0,698 & 0,622 & 0,797 & 0.676 & 0,60 & 0,56 & 13,57 & 75,56 \\
\hline 3 & $\begin{array}{l}\text { Mirassol } \\
\text { do Oeste }\end{array}$ & $92.484,2$ & 86,2 & 20,3 & 0,739 & 0,674 & 0,825 & 0,719 & 0,56 & 0,60 & 13,93 & 36,18 \\
\hline 4 & $\begin{array}{c}\text { Alto } \\
\text { Taquari }\end{array}$ & $119.506,9$ & 82,4 & 8,5 & 0,804 & 0,777 & 0,845 & 0,791 & 0,54 & 0,70 & 23,72 & 78,84 \\
\hline 5 & Luciara & $35.932,2$ & 9,5 & 3,5 & 0,691 & 0,589 & 0,853 & 0,631 & 0,59 & 0,58 & 13,86 & 67,28 \\
\hline 6 & Cotriguaçu & $85.474,2$ & 8,4 & 7,9 & 0,721 & 0,678 & 0,756 & 0,728 & 0,45 & 0,63 & 23,78 & 91,42 \\
\hline 7 & Aripuanã & $249.966,8$ & 7,8 & 5,0 & 0,704 & 0,655 & 0,741 & 0,715 & 0,63 & 0,58 & 16,21 & 27,98 \\
\hline 8 & Apiácas & $138.815,6$ & 6,8 & 5,1 & 0,713 & 0,659 & 0,783 & 0,698 & 0,62 & 0,57 & 11,63 & 0,46 \\
\hline
\end{tabular}


Na tabela 2 (Anexo A) foi analisado o comportamento de alguns indicadores sociais, ambientais e econômicos dos 10 municípios mais desmatados relativamente no período entre 1993 - 2003, além de índices que revelam a desigualdade de renda. Como foi dito anteriormente, esse período foi bastante dinâmico em relação à conversão de novas áreas para pecuária (abertura da fronteira), como para agricultura (pressão sobre a fronteira $)^{4}$.

$\mathrm{Na}$ análise, nota-se que em todos esses municípios, com exceção de Guarantã do Norte, a proporção entre os $20 \%$ mais ricos em relação aos $40 \%$ mais pobres aumentou. Além disso, igualmente o índice de Gini piorou seus números em todos esses municípios, novamente com exceção de Guarantã do Norte. Esses dados revelam claramente que houve, na década de 90 e o início do novo século, uma concentração de renda nos dez municípios mais desmatados, independente da atividade.

Além disso, os municípios de Sorriso e Tapurah são os únicos a apresentarem IDH e renda per capita acima das médias nacional e estadual. Coincidentemente, são os dois municípios que têm no complexo agrícola (soja/algodão) sua principal fonte de renda. Os dados também indicam uma conjuntura bem favorável a esses municípios, pois ambos receberam no ano de 2003 quantias bem superiores dentro do sistema de financiamentos concedidos, sobretudo Sorriso que, sozinho, recebeu $53 \%$ a mais que todos os outros juntos. A outra face dessa abundância é a quantidade do passivo e degradação ambiental observados: Sorriso, dentre os mais desmatados nesse período, é o município que possui o maior passivo ambiental, já que se localiza praticamente em área de floresta e já possuía até 2003, 74,3\% de área convertida. Além disso, é campeão estadual na quantidade de focos de calor e no número de empresas que vendem agrotóxicos.

Esse exercício empírico nos revela um panorama inicial no qual, segundo o paradigma da sustentabilidade, o desenvolvimento para ser alcançado, não pode se ater somente ao fator econômico. Enquanto as racionalidades ecológica e social não comandam o processo de desenvolvimento, deveria haver uma agenda política que favore- cesse outras atividades econômicas menos intensivas em recursos naturais, com maior valor agregado e menor concentração de renda. No entanto, é decisivo, em uma democracia, maiores espaços de participação para que as pessoas possam escolher, inclusive, o tipo de desenvolvimento que desejam.

\section{Conclusão}

Esse exercício empírico revela, num panorama inicial, que não há diferenças socioeconômicas muito marcantes entre municípios que foram desmatados com maior ou menor intensidade, sobretudo entre aqueles onde a atividade econômica predominante é a pecuária (bovinocultura), questionando a idéia de que "desmatamento significa progresso". Por outro lado, há ainda uma forte assimetria em relação aos municípios onde a agricultura (soja) é o principal produto. Nesses municípios, a dicotomia da modernidade (crescimento versus conservação) parece estar bem viva. Os melhores indicadores socioeconômicos foram encontrados nos municípios com piores indicadores ambientais (desmatamento/queimadas/venda de agrotóxicos) e, ainda, estes são os municípios que recebem o maior volume de financiamentos de bancos privados e públicos.

Esses dados reforçam a hipótese de Caio Prado Jr. (1998, p.72) sobre a insustentabilidade desses ciclos econômicos voltados para fora.

Em tais condições, a economia brasileira não terá outros horizontes que monotonamente se repetir e evoluir através de sucessivos ciclos estreitamente subordinados a conjuntura do mercado externo para um ou outro gênero primário de produção colonial. Ciclos esses que em uma fase de prosperidade momentânea é seguida e substituída por outra de declínio, decadência e, em casos extremos, até mesmo decomposição econômica e social.

Nesse caminho do agronegócio, a riqueza gerada é extremamente concentrada, reafirmando um quadro histórico no país. Deste modo, este não é um ciclo econômico que provoque mudanças na estrutura social, pelo contrário, acentuam-se as diferenças disfarçadas atrás de um PIB médio elevado, o que acaba enviesando o IDH. Não se perce- 
be, nesse cenário, nenhum apoio mais efetivo à organização da agricultura familiar, por exemplo. E, finalmente, cabe ressaltar o que foi dito, no sentido de que, ao se adotar um modelo de produção baseado naquele dos países de centro, estamos desconsiderando todo nosso patrimônio natural, que jamais será recuperado. Se for verdade que o argumento econômico ainda é o que mais induz às transformações, devemos considerar, como forte possibilidade, que o próximo ciclo econômico, provavelmente seja a venda dos serviços dessa floresta que hoje está sendo convertida em nome da abundância. Ainda é possível fechar a caixa de Pandora, não antes de resgatar a esperança numa sociedade mais justa e sustentável ambientalmente.

\section{Notas}

${ }^{1}$ Segundo Rawls os bens primários são direitos, liberdades e oportunidades, renda e riqueza e as bases sociais do respeito próprio. A crítica de Sen é que esses bens primários são sujeito a uma infinidade de variações (heterogeneidade pessoais, diversidades ambientais, variações no clima social, diferenças de perspectivas relativas e distribuição na família) o que dá uma perceptiva de relativismo ao que seja bem primário, não devendo homogeneizá-los, mas sim os considerá-los de acordo com a vida que o individuo valoriza (SEN, 2000, p.92-93).

2 Deve-se ressaltar que nessa época, 1930, o estado do Mato Grosso ainda não havia sido dividido. Essa divisão político -administrativa acontece em 1979.

${ }^{3}$ Há várias críticas a esses programas, notadamente, por terem oferecido crédito com taxas fixadas em níveis bastante reduzidos e sem correção. Além disso, percebe-se que houve privilégio de acesso a grandes grupos econômicos e os objetivos iniciais dos programas não foram alcançados. Para maiores detalhes, consultar Mueller, Wright e Nogueira (1986).

${ }^{4}$ Há muita controvérsia sobre quem é responsável pelo desmatamento inicial e sem entrar nessa polêmica particularmente, é importante ressaltar que a pratica mais comum na região ainda é a extração de madei- ra, sucedida pelo desmate feito pela pecuária e, dependendo da região e de suas características físicas, a apropriação pela soja. Assim, a soja potencializa a escala do processo de desmatamento, aumenta a velocidade das mudanças do uso do solo e empurra a fronteira da pecuária, mantendo uma relação direta e indireta com o desmatamento (FBOMS, 2004).

\section{Referências}

BERTRAM, Paulo. Uma introdução à história econômica do Centro-Oeste do Brasil. Brasília: CODEPLAN; Goiás: UCG, 1988.

FÓRUM Brasileiro de organizações não-governamentais e movimentos sociais para o meio ambiente e o desenvolvimento (FBOMS). Grupo de Trabalho Florestas. Relação entre cultivo de soja e desmatamento (sumário executivo). Supervisão: Weber Amaral; Roberto Smeraldi, 2004.

FURTADO, Celso. Introdução ao desenvolvimento: enfoque histórico-estrutural. 3. ed. Rio de Janeiro: Paz e Terra, 2000 .

GRAZIANO DA SILVA, J. A nova dinâmica da agricultura brasileira. 2. ed. Campinas-SP: UNICAMP.IE, 1998.

MORENO, G.; HIGA, T.C.S. Geografia de Mato Grosso: território, sociedade, ambiente. Cuiabá: Entrelinhas, 2005.

MÜLLER, C.C.; WRIGHT, C.; NOGUEIRA, J.M. O processo de formação de políticas agrícolas no Brasil. Relatório Final IPEA/IPAN. Brasília, 1986.

SACHS, Ignacy. Estratégias de transição para o século XXI. In: BURSZTYN, Marcel (org.). Para pensar o desenvolvimento sustentável. São Paulo: Brasiliense, 1993.

PRADO JR., Caio. História e desenvolvimento. São Paulo: Brasiliense, 1999.

SANTOS, Boaventura de Sousa. A crítica da razão indolente: contra o desperdício da experiência. 3.ed. São Paulo: Cortez, 2001. vol. 1, cap. 1.

SEN, Amartya. Desenvolvimento como liberdade. São Paulo: Companhia das Letras, 2000.

SUNKEL, Osvaldo. El marco histórico del proceso de desarrollo y de subdesarrollo. Santiago: CEPAL, 1967.

VEIGA, José Eli. Desenvolvimento sustentável: o desafio do século XXI. Rio de Janeiro: Garamond, 2005. 